\title{
La $58^{\mathrm{a}}$ reunión de la ONU: Reforma y contrarreforma
}

Francisco Javier IbISATE

\section{"Llega el Sur"}

¿Para qué sirven los magros éxitos de las cumbres mundiales?. La respuesta es una paradoja: para no perder la esperanza; para profundizar la idea de que "otro mundo mejor es posible". La OMC de Cancún se cierra en rotundo fracaso. La reunión del FMI y BM en Dubai pasa, una vez más, sin pena ni gloria. En la conferencia de Nueva York la diatriba se centra más en el descalabro de Irak que en la necesaria refundación de las Naciones Unidas. El voto unánime de los 15 miembros del Consejo de Seguridad, que transforma una "fuerza ocupacional" en "fuerza multinacional" no encaja bien con el derecho internacional y en nada justifica la ilegalidad de la "guerra preventiva" contra Irak. Las razones de la 'diplomacia' dejan en entredicho los valores morales y, a este respecto, ha demostrado mayor moralidad el G-20 (menos 1) al decir "no" en Cancún, que el grupo de los 15 al decir "sí" en Nueva York. Sin embargo, el fracaso no puede ser la última respuesta a los problemas de la historia. La verdadera respuesta es la "reforma" de las instituciones que derivan en un fracaso. Lo que realmente está en crisis es el actual orden internacional, que sostienen esas instituciones, y la gran novedad es que el Sur es quien lo quiere reformar. Este es el mensaje de una editorial que lleva por título: "Llega el Sur". 
"El interminable debate sobre Irak ha escondido en las últimas semanas la gran transformación en curso al interior de la escena internacional. La venida de los nuevos Grandes, que llegan del Sur. Saben que cuestionan la preponderancia de los Estados Unidos, de Europa, de Rusia, es decir, del Norte. El poder de estas nuevas potencias no es reciente. Pero se han manifestado con fuerza en tres momentos sucesivos: primero en Cancún, en la cumbre de la Organización Mundial del Comercio (OMC); después, esta semana en Nueva York, al inicio de la reunión de otoño de la Asamblea General de la ONU; también, en las mismas fechas, en Dubai, con ocasión de la sesión del Banco Mundial y del Foro Monetario Internacional".

"Tres países llevan el liderazgo, India, Brasil y África del Sur; tres democracias, tres economías de mercado, representan a tres continentes. Les siguen otros muchos países, desde México hasta Indonesia, desde Egipto hasta Nigeria, a veces, aunque no siempre, apoyados por China. Reunidos, integran dos tercios de la humanidad, para quienes el orden de prioridades en el mundo de hoy no es situarse a favor o en contra de la guerra de Irak, en el campo Chirac o en el campo Bush, ni tampoco emprender una hipotética "guerra contra el terrorismo". Lo que quieren es modificar las reglas del juego internacional a favor de lograr un objetivo: el desarrollo, la lucha contra la enfermedad, la miseria, el analfabetismo, que sienten ser peligros mucho más serios que el pretendido arsenal de armas de destrucción masiva que pudo haber tenido Irak. Sus intereses pueden diferenciarse. No son antieuropeos, antiamericanos o antirusos. Están de acuerdo en que las potencias surgidas de la segunda guerra mundial - cada vez menos representativas demográficamente- no retengan más tiempo el monopolio del poder en las organizaciones internacionales. Quieren la parte del poder que corresponde a quienes ellas representan hoy día”.

"Quieren hacer sentir su influjo en el engranaje de toma de decisiones colectivas, sea cual sea el foro. Esto ha sido relativamente fácil en la OMC, donde cada país tiene un voto y donde el Sur (con razón o sin ella; cuestión a discutir) creyó conveniente hacer tambalear a Cancún, contra la Unión Europea y los Estados Unidos. Tarea más difícil al interior de la ONU, donde el Consejo de Seguridad refleja la configuración de las potencias surgidas luego de la segunda guerra mundial; Estados Unidos, Rusia, China, Gran Bretaña y Francia retienen su puesto y sólo ellas disponen del derecho de veto. Esa es la 
razón que movió en la presente semana a Brasil, Africa del Sur y la India a manifestar su voluntad de tener también ellas un asiento permanente. De igual manera estos tres países han reclamado, esta semana, en Dubai disponer de más votos en los consejos de administración del Banco Mundial y del Fondo Monetario. No van a reducir su presión. Su causa es justa. $\mathrm{Y}$ va a ser necesario tomarlos en cuenta, porque, con razón, llaman a la puerta de los Grandes". (Le Monde, 29.09.03).

Era de esperar que en la conferencia de Naciones Unidas afloraran estos problemas de las economías del Sur, problemas derivados de la globalización y del asimétrico comercio internacional, pobreza, desempleo, deuda externa, crecientes pandemias, inseguridad económica..., por cuanto eran parte de la agenda y de los compromisos firmados en "La Declaración del Milenio", emitida en septiembre 2000. Como veremos, esa era la intención del secretario general Koffi Annan. Sin embargo, la atención de la ONU 2003 se centró en temas relativamente urgentes, como la función y la responsabilidad de Naciones Unidas en la fase de pacificación y estabilización política y económica en el conflictivo Irak, así como una reestructuración más representativa del Consejo de Seguridad. No es que haya sido tiempo perdido porque, en cierto sentido, se sentó a Estados Unidos en el banquillo de los acusados. Esto significa que, una vez terminada la cumbre de Nueva York, países del Sur se reagrupan para mantener viva la conciencia internacional. Por ello, hacemos dos breves paréntesis.

\section{El G-22 se reagrupa}

No podemos decir que Cancún ha sido el principio del fin y que la causa del Sur se ha perdido. Si bien es cierto que nuestro TLC con Estados Unidos queda sometido "a la lupa de R. Zoellick" y que sus negociaciones son presiones, sin embargo, el G-20 plus, que ha perdido algunos de sus miembros, se reagrupa bajo la iniciativa de Brasil. "Los países del Sur se vuelven a reunir para afinar su estrategia después de Cancún", y nosotros volvemos a contemplar el comercio internacional desde una perspectiva mundial, no sólo regional. Esta noticia no será del agrado de P. Lamy y R. Zoellick que irónicamente se referían al "G- cualquier cosa". A iniciativa de Brasil se reunieron en Ginebra, el 3 de octubre, los embajadores del G-22 y el 10 de octubre se congregaron en Buenos Aires los ministros de Asuntos Exteriores, 
con sus homólogos de China y Egipto, "para definir una oposición en la perspectiva de nuevas negociaciones y para hacer propuestas sobre la reforma de la OMC".

El director de la OMC ha dicho en Ginebra que si Cancún "no ha sido un fracaso, sí ha supuesto un revés al ciclo de Doha". El personal técnico de la OMC piensa que realmente se trata de un fracaso, por culpa de todo el mundo. Europeos y norteamericanos, que, "bajo la presión de sus lobbys agrícolas, no han cedido nada". Brasil y la India, "por haber atizado las pasiones de los países pobres". Los africanos, "porque no entendieron que perdían todo y nada ganaban en caso de fracaso". Sobre todo algunas ONG que, de acuerdo a este personal, "erraron el blanco y en vez de arremeter contra los verdaderos culpables, se empeñaron en destruir la OMC". Los representantes en Ginebra han aprendido una lección: "Cancún nos ha hecho ver la realidad. Sabemos que no estamos preparados para plantear decisiones importantes en materia de comercio internacional. Necesitamos un tiempo para digerir esta realidad desapercibida antes de Cancún".

Los africanos creen que ellos han perdido más que los demás. "Estamos dispuestos a reiniciar las negociaciones y hacer concesiones, a condición de que se nos asocie al proceso de toma de decisiones". Al mismo tiempo se alegran de la unidad, sin precedentes, de los países del Sur. "Durante años hemos permanecido fragmentados frente a los gigantes de Occidente. Aquí hemos negociado como socios iguales. Hemos dado a conocer nuestro mensaje: las masivas subvenciones agrícolas del Norte son un importante factor de desestabilización de los países pobres. Esto significa que no tenemos otra alternativa que reiniciar las negociaciones". El director de la OMC comunica que ha sondeado el parecer de muchos ministros, que "quieren reiniciar" las negociaciones, aunque "son grandes las discrepancias y las expectativas. Hará falta mucho tiempo para encarrilar las negociaciones y la organización debe analizar sus propias debilidades". (Le Monde, 10.10.03).

A modo de paréntesis, desde la perspectiva del comercio internacional y de sus tratados de libre comercio en Latinoamérica, nos llega desde el Sur un comunicado de los delegados episcopales sobre el gran proyecto del gobierno de los Estados Unidos y asociados: "El ALCA y el futuro de nuestros pueblos". El documento es importante 
porque refleja el sentimiento de "los pueblos" y puede iluminar la conciencia de bastantes gobiernos e instituciones que ven ahí la solución de nuestros problemas económicos y sociales. Escrito en vísperas de la OMC de Cancún, nos refleja a nivel latinoamericano el mismo problema internacional.

“1. Del 2 al 4 de septiembre nos reunimos en la ciudad de Montevideo obispos representantes de las Conferencias Episcopales de los países del Mercosur, Chile y Bolivia, para reflexionar sobre algunos desafíos éticos y pastorales que supondría la implementación del ALCA (Área de Libre Comercio de las Américas) en nuestra región. 2. No ignoramos la complejidad y las diversas percepciones que suscita en la sociedad. Por eso pensamos que es necesario no sólo un análisis técnico-económico, sino también ético-social de la cuestión. 3. Nos preocupa en primer lugar la insuficiente información y la rapidez con la que se impulsa dicho proyecto, con la consiguiente falta de participación de todos los sectores de la sociedad civil en una toma de decisión tan importante para el futuro de nuestros pueblos. 4. Una eventual integración de los países americanos debería tener en cuenta no sólo el aspecto económico y comercial, sino todas las dimensiones de la persona humana: sociales, políticas, culturales y religiosas. 5. La excesiva desproporción de las capacidades competitivas entre nuestros países, algunos de ellos con economías muy fuertes y desarrolladas, otros muy débiles, y el desequilibrio de intereses y poderes, podrían traer conseçuencias muy graves especialmente en relación a la identidad cultural, los puestos de trabajo y la misma subsistencia de las economías más frágiles. Más que una integración podría tratarse de un neocolonialismo con un impacto negativo sobre las comunidades locales. 6. Este proyecto tendería a propiciar una concentración del poder económico en pocas manos y en pocas empresas competitivas, favoreciendo la formación de monopolios y oligopolios, que terminarían por imponer su hegemonía a los gobiernos, especialmente en los países más débiles del continente americano. 7. Nos preocupa también la situación en la que se encontrarían economías muy elementales pero que pertenecen a la identidad cultural de nuestros pueblos, como las de los aborígenes o las comunidades rurales, que en este sistema correrían el riesgo de ser desplazadas o anuladas. 8. Un proyecto como el ALCA debería tener como primera motivación la promoción del bien común y de la solidaridad entre los pueblos y no

La $58^{2}$ reunión de la ONU: Reforma y contranelorma 
la búsqueda del mayor provecho de algunos pocos y de los más poderosos en detrimento de los débiles. 9. Puede parecer que la implementación del ALCA es irreversible. Sin embargo, es también posible cambiar algunos de los términos para que los países en vías de desarrollo tengan preferencias competitivas, se respete su soberanía y autodeterminación y sus recursos naturales estratégicos no sean susceptibles de apropiación privada. En este sentido es importante reconocer y participar en la construcción y fortalecimiento de bloques regionales y subregionales en nuestro continente. 10. Un verdadero proceso de integración de América debe basarse en una política continental que tenga en cuenta los derechos humanos y los principios de la soberanía, la justicia, la solidaridad y el respeto a las identidades culturales de los pueblos. 11. Una vez más afirmamos, inspirados en la Doctrina Social de la Iglesia, que la economía debe estar al servicio de la persona humana y respetar los derechos fundamentales de los pueblos". (Zenit, 14.09.03).

\section{Enfrentar todas las amenazas}

Un mes antes de iniciarse la $58^{\mathrm{a}}$ conferencia de las Naciones Unidas, su Secretario General quiso hacer presentes ese cúmulo de problemas del bloque Sur, enumerados en La Declaración del Milenio 2000, y que habían quedado pendientes de una respuesta colectiva. Con fecha 8 de septiembre, Kofi Annan presenta su informe sobre el estado de la comunidad internacional, anunciando una "reforma radical" para salvar la ONU. Como dijera un embajador: "el problema no es la ONU; el problema es el mundo". El tema central es el sistema de seguridad colectiva heredado de la segunda guerra mundial. Kofi Annan se pregunta: "¿Cómo podrá funcionar si las diferentes regiones del mundo no tienen la misma percepción de qué es lo que les amenaza? Estamos de acuerdo sobre la existencia de nuevas amenazas, pero parece que no estamos de acuerdo sobre su naturaleza, sobre la respuesta y, en concreto, sobre cómo dar una respuesta colectiva. Existen las que yo llamaría amenazas "duras": las armas de destrucción masiva y el terrorismo; existen también las amenazas "blandas": la pobreza, la privación, el sida. Con franqueza, si se hiciera un sondeo en todas las regiones del mundo no estoy seguro de que las armas de destrucción masiva o el terrorismo aparezcan en primer lugar". (Le Monde, 09.09.03). 
Kofi Annan vuelve sobre esta misma preocupación en su discurso de apertura de la $58^{\mathrm{a}}$ Asamblea General de las Naciones Unidas. "Tenemos que enfrentar nuevas amenazas, o tal vez antiguas amenazas extraña y peligrosamente combinadas: las nuevas formas de terrorismo, proliferación de armas de destrucción masiva. Pero, mientras que para algunos es evidente que estas amenazas son el desafío mayor a la paz mundial y a la seguridad, otros se sienten directamente más amenazados por pequeñas armas en sus conflictos civiles, o por lo que se denominan "amenazas blandas", como la persistencia de la extrema pobreza, la disparidad de ingresos dentro y entre las sociedades, la difusión de las enfermedades infecciosas, el cambio climático y el deterioro ambiental. En realidad, no podemos escoger. Las Naciones Unidas tienen que enfrentar todos los desafíos, los nuevos y los antiguos, las amenazas duras y las amenazas blandas". (Le Monde, 23.09.03).

Se entiende mejor el sentido de estas afirmaciones si recordamos unas frases del discurso de Kofi Annan en la cumbre de 2000. "Afrontamos desafíos mundiales que nos obligan a trabajar juntos y si esto es cierto en la esfera económica, lo es aún más ante el desafío que representan las matanzas y las guerras. El instinto de solidaridad humana, que impulsa a algunos Estados a acudir en ayuda de los ciudadanos de otros Estados o a presentar cargos contra sus antiguos dictadores, es digno de alabanza. Pero cuando estas acciones las aplican uno o pocos Estados en nombre de su propia autoridad, traen consigo el riesgo de la anarquía mundial". Clara referencia a la guerra de Servia Kosovo y al dictador Slobodan Milosewic. Kofi Annan pidió entonces a los Estados la urgente ratificación de los estatutos de la Corte Penal Internacional (CPI), "que juzgue a los genocidas, que los tribunales nacionales no pueden o no quieren juzgar. El mundo estará más seguro si sabe que la ONU puede intervenir cuando están amenazados por una destrucción masiva". Este será uno de los puntos candentes en la presente reunión de las Naciones Unidas, que algunos dignatarios no han querido entender.

Hay gobiernos, entre los más poderosos que sufren de amnesia histórica, para quienes las amenazas duras - las del 11 septiembreson el desafío número uno mundial. En su discurso en la ONU, nuestro señor presidente se hizo portavoz de esos o de ese gobierno. "No es posible que este foro se paralice en debates cuando se trata de 
liberar a una nación de una tiranía. Todos debemos actuar frente a la opresión. El terrorismo es una negativa de todos los valores que compartimos". Así se justifica que el gobierno de El Salvador se aliara de acólito con el gobierno de Estados Unidos en la negativa de firmar y ratificar los estatutos de la Corte Penal Internacional. Por añadidura nuestro señor presidente logró convencer a algunos de sus oyentes y traductores de que en nuestro país no existen las "amenazas blandas" y que en El Salvador "otro mundo mejor es imposible".

Creyendo interpretar la "reforma radical" de Kofi Annan, nuestro presidente dijo: "Lo que no admite discusión es que este foro no estaba a la altura de las exigencias de un mundo cada vez más complejo". Qué fácil condenar en dos líneas la historia humanitaria de las Naciones Unidas. Estas dos líneas nos dejan varios interrogantes: ¿quiénes son los miembros de este foro que no están a la altura?; ¿cuáles son las exigencias y cuáles los problemas de este mundo complejo?. En su discurso se olvidó de citar los verdaderos problemas de su país y también los graves problemas que había suscrito dos años antes en la cumbre del Milenio. Nuestro presidente sufre de amnesia histórica.

En la Declaración del Milenio los "miembros de este foro" se habían comprometido a defender los siguientes valores: la libertad, la igualdad, la solidaridad, la tolerancia, el respeto de la naturaleza, la responsabilidad común. Los problemas de un mundo "cada vez más complejo" son: "La paz, la seguridad y el desarme. El desarrollo y la erradicación de la pobreza. La protección de nuestro entorno común. Los derechos humanos, democracia y buen gobierno. La protección de las personas vulnerables. La atención a las necesidades especiales de Africa. El fortalecimiento de las Naciones Unidas". ("Entorno económico mundial". UCA Editores 2003; pp. 201-211) Por desgracia todo este cúmulo de problemas (amenazas duras y blandas) se encarrilaron a la vía muerta para centrarse en la liberación y estabilización de Irak, porque un gran país es tan poderoso para armar la guerra como incapaz para organizar la paz. El gran problema es lo que está debajo de este problema.

\section{La guerra preventiva en el banquillo de los acusados.}

Es necesario volver a recordar este cúmulo de críticas, desde dentro y desde fuera de los Estados Unidos, a su teoría de la "guerra 
preventiva" porque la unánime aprobación del Consejo de Seguridad a la propuesta del gobierno Bush sobre Irak podría dar a entender, a ese gobierno y asociados, que el fin justifica todos los medios. Kofi Annan actualiza su doctrina sobre la guerra preventiva, expresada en el año 2000: "Pero cuando estas acciones las aplican uno o pocos Estados en nombre de su propia autoridad, traen consigo el riesgo de la anarquía mundial".

En la actual conferencia K. Annan cuestiona la guerra preventiva defendida por Estados Unidos. "Desde la fundación de esta institución los Estados han procurado enfrentar las amenazas a la paz por medio de la contención y disuasión basada en un sistema de seguridad colectiva, de acuerdo a la Carta de las Naciones Unidas. El artículo 51 prevé que todos los Estados, si son atacados, tienen el derecho de defenderse. Hasta ahora estaba admitido que, cuando los Estados se exceden y deciden recurrir a la fuerza para responder a graves amenazas a la seguridad y a la paz internacional, necesitan contar con la legitimidad que sólo pueden procurar las Naciones Unidas".

"Ahora, algunos dicen que esta teoría no es sostenible cuando un ataque armado de destrucción masiva puede lanzarse en cualquier momento, sin previo aviso o por un grupo clandestino. Los Estados, arguyen, tienen el derecho y la obligación de utilizar la fuerza de manera preventiva, incluso sobre el territorio de otros Estados y aun cuando los sistemas de armas utilizables en el ataque estén en proceso de fabricación. Esta lógica representa un cambio fundamental respecto a los principios sobre los que reposaba la paz y la estabilidad del mundo, desde hace cincuenta y ocho años, aunque haya sido de manera imperfecta. Lo que me inquieta es que, si se adopta este principio, pudiera crear precedentes que multiplicarían el recurso a una fuerza unilateral y sin fundamento jurídico, con o sin ninguna justificación". (Le Monde, 23.09.03).

El gobierno de Estados Unidos, y asociados, se resisten a aceptar, pese a todas las evidencias, que la guerra preventiva contra Irak carecía de toda justificación real y legal. Todavía recordamos los falsos testimonios blandidos por C. Powell: "Si el régimen iraquí no se desarma en esta ocasión, será desarmado después. No nos resistimos a hacer la guerra si ésta es la única manera de arrancar a Irak sus armas de destrucción masiva"... Hussein tiene "claros contactos con grupos 
terroristas, entre ellos Al Qaeda” (ECA 2003; p. 391) Un grupo de 41 Premios Nobel norteamericanos se oponen a esta guerra: "Los abajo firmantes se oponen a una guerra preventiva contra Irak, desprovista de un amplio apoyo internacional. Las operaciones militares contra Irak pueden ciertamente conducir a una victoria contundente en poco tiempo. Pero la guerra se caracteriza por la sorpresa, la pérdida de vidas humanas y los resultados imprevistos. Incluso con una victoria creemos que las consecuencias médicas, económicas, ambientales, morales, espirituales, políticas y legales de un ataque preventivo podrían erosionar, en lugar de proteger, la seguridad y la influencia de Estados Unidos en el mundo". (Ibídem; p. 393) Éste ha resultado ser un anuncio profético.

El profesor emérito de Georgetown, Norman Birbaum, fustiga a Bush y a los ocho dignatarios que apoyaron la guerra preventiva: "El presidente Bush sostiene que nuestro país tiene derecho a eliminar a enemigos en potencia mediante ataques preventivos. La proclamación del derecho de ataque preventivo por parte de una nación contra otra es un asalto definitivo contra la dolorosamente construida estructura del derecho internacional. Es una invitación a que otros países hagan lo mismo. Estados Unidos ya ha transgredido el derecho internacional con el trato dado a los prisioneros que ha hecho en Afganistán o que han sido capturados por gobiernos aliados en otras partes. Aceptan ustedes, con pasmosa tranquilidad, la afirmación de que "el régimen iraquí y sus armas de destrucción masiva representan una clara amenaza para la seguridad mundial. Repiten algo que no es mas que una ficción de la Casa Blanca, que Irak respalda a Al Qaeda. No hay pruebas convincentes de ninguno de los dos argumentos. Tratan ustedes la obsesión del presidente Bush como algo racional". (Ibidem; p. 394) Esta carta de Norman Birbaum, al mismo tiempo que prueba el engaño y autoengaño de la administración Bush, es una muestra del poderoso influjo de los medios de comunicación social fuera de los Estados Unidos.

La administración estaba decidida a iniciar la guerra aunque no había constancia de la existencia de armas de destrucción masiva. Los inspectores de armas de Naciones Unidas afirmaron que "después de sesenta días de investigaciones en Irak podían concluir con certeza que Hussein no tiene en vigencia programas de desarrollo de armas químicas, pero que no hay certeza de que tenga armas químicas o 
biológicas, por lo que solicitan más tiempo para corroborarlo o desmentirlo". (Ibidem; p. 392) Conviene recordar que seis meses después, el 3 de octubre, David Kay, jefe del grupo de inspección, 1.400 especialistas norteamericanos e ingleses, declara: "No hemos encontrado hasta este día armas de destrucción masiva, aunque tenemos indicios de la voluntad de producirlas en el futuro". Este informe ha disgustado a bastantes senadores. David Rockefeller ha dicho: "Si se decidió ir a la guerra invocando la lucha contra el terrorismo mundial, era necesario tener certeza de la existencia en Irak de armas biológicas, nucleares o químicas. Creo que todo esto cuestiona la doctrina del ataque preventivo, así como la manera en que se toman las decisiones al más alto nivel del Estado". Ni entonces, ni ahora hay pruebas reales de la existencia de armas de destrucción masiva.

La última etapa del proceso de engaño y autoengaño era desprestigiar al Consejo de Seguridad, tachándolo de irresponsable, al mismo tiempo que se profesa un fingido respeto por las Naciones Unidas. En su discurso al pueblo norteamericano, 16,03,03, Bush decide unilateralmente iniciar la guerra: "Estados Unidos de América tiene la autoridad soberana de utilizar la fuerza para proteger su seguridad nacional. Norteamérica ha procurado trabajar con las Naciones Unidas para enfrentar esta amenaza porque queremos arreglar el problema de manera pacífica. Nosotros creemos en la misión de las Naciones Unidas... Pero algunos miembros permanentes del Consejo de Seguridad han anunciado que opondrán su veto a cualquier solución que obligue al desarme de Irak. Estos gobiernos comparten nuestro análisis del peligro, pero no muestran determinación para enfrentarlo. Sin embargo, muchas naciones tienen la determinación y la fuerza moral para enfrentar esta amenaza a la paz, y se está formando una amplia coalición para aplicar las justas demandas del mundo. El Consejo de Seguridad de Naciones Unidas incumplió sus responsabilidades y, por tanto, nosotros vamos a asumir las nuestras". (Ibidem; p. 396)

Este discurso de Bush está plagado de hipocresía, falsas acusaciones y de inmoralidad. G.W. Bush lanza este discurso la víspera del día en que Hans Blix, jefe de inspectores de la ONU, presentaría su informe certificando que no habían descubierto la existencia de armas de destrucción masiva. Acusa falsamente al "pacto franco-alemán" de vetar el desarme de Irak, cuando Chirac y Schroder estaban ofrecien- 
do apoyar con sus aviones Mirage y otras ayudas técnicas a los inspectores de Naciones Unidas. Silencian, sin el menor respeto y decoro, no los miles, sino los millones de manifestantes pacíficos ("no war") en todas las grandes y menores capitales del mundo entero, y desoyeron las repetidas llamadas del Papa Juan Pablo II a la paz: "Quien decida que todos los medios pacíficos de los que dispone el derecho internacional se han agotado tendrá que asumir una grave responsabilidad ante Dios, ante su propia conciencia y ante la historia”. La administración Bush no está dando muestra alguna de que les remuerda la conciencia, pero lo realmente cierto es que la historia no está de su lado. A nivel mundial está creciendo el sentimiento antinorteamericano y dentro de Estados Unidos desciende la popularidad del presidente G.W. Bush.

\section{La crisis de Irak en el centro del debate}

Todavía recordamos las últimas frases del discurso del pasado 16 de marzo. Bush exhorta a extranjeros, periodistas e inspectores de Naciones Unidas a abandonar Irak lo antes posible "por su propia seguridad". Comunica al pueblo iraquí que escuchen la radio y su mensaje para que entiendan que la posible campaña militar es contra los hombres sin fe y sin ley que dirigen al país. Proporcionará alimentos, medicinas y ayudará a reconstruir la nación. "El día de la liberación está cerca". Bush invita a los soldados a dejar entrar en forma pacífica a las fuerzas de la coalición y a no quemar los pozos de petróleo, la gran riqueza del país. "Estados Unidos, junto con otros países, va a trabajar para hacer progresar la libertad y la paz en la región. Que Dios bendiga a Norte América". (Ibidem; p. 396)

Si las dos primeras semanas dieron la impresión de que la ocupación de Irak sería "lłegar, ver y vencer", a medida que pasa el tiempo se cumple, al pie de la letra, la predicción de los 41 Premios Nobel de EEUU: "Incluso con una victoria creemos que las consecuencias médicas, económicas, ambientales, morales, espirituales, políticas y legales de un ataque preventivo podrían erosionar, en lugar de proteger, la seguridad y la influencia de Estados Unidos en el mundo". Palabra por palabra, en cada uno de estos rubros, ha quedado desprestigiada la administración Bush. En los meses de agosto y septiembre aumentan cada día los ataques a la coalición, hasta 22 ataques por día, con el agravante de que la historia se vuelve a repetir en Afganistán. Sólo en 
la infructuosa búsqueda de armas en Irak ya se han gastado $\$ 300$ millones y quedarían por gastar otros $\$ 300$ millones (Le Monde, 03.10.03), y el presidente Bush ha pedido al Congreso $\$ 87.000$ millones para la reconstrucción de Irak y Afganistán. (El País, 24,09,03) Aparte de las consecuencias médicas, medio ambientales, morales y espirituales para la población iraquí y para los temerosos e inseguros soldados de la coalición, la administración Bush se siente desconcertada ante el complejo mosaico de grupos étnicos, religiosos y políticos, que difícilmente aceptan al Consejo Provisional presido por Ahmad Chalabi y socios importados por los Estados Unidos e Inglaterra.

No es errado decir que la administración Bush presenta síntomas del "síndrome de Vietnam". Comienzan a entender que construir la paz les cuesta tanto o más que hacer la guerra, en términos económicos y sobre todo en términos de aceptación y les humilla el tener que solicitar y "más bien exigir", una colaboración multilateral de las $\mathrm{Na}$ ciones Unidas. Pero esta solicitud de ayuda, esta conversión al multilateralismo, no significa un reconocimiento de los errores cometidos, sino una especie de derecho internacional porque ellos se han comprometido en una guerra necesaria para la paz y la libertad mundial. Estas tensiones se hacen presentes en la reunión convocada por K. Annan, en Ginebra, el 13 de septiembre. Francia, Alemania y luego se unirá Rusia no aceptan la propuesta del gobierno Bush enviado al Consejo de Seguridad de la ONU: colaboración multilateral de Naciones Unidas, pero bajo el comando de Estados Unidos. "Esperamos, dijo Bush, que Francia y Alemania van a contribuir a la reconstrucción de Irak, porque les conviene hacerlo. Estamos abiertos a que nos hagan sugerencias". (Le Monde, 11 y 15.09.03). La breve reunión de Ginebra presagiaba las fuertes tensiones en la cumbre de Nueva York. Pero antes, un breve paréntesis.

\section{La "reforma de la ONU" a la papelera de reciclaje}

Antes de avanzar hay que hacer un triste paréntesis. La $58^{\mathrm{a}}$ conferencia de las Naciones Unidas se centró en la crisis de Irak y la anunciada "reforma de la ONU" fue a parar a la papelera de reciclaje. El diario Le Monde presentaba, en nueve páginas, un "Documento sobre la Reforma de la ONU" (20.09.03), concretando la propuesta que hiciera Kofi Annan en la cumbre del Milenio. "Hay que reinventar las

La $58^{\circ}$ reunión de la ONU: Relorma y contronelorma 
Naciones Unidas. En los últimos 55 años una población de 6.000 millones duplica el número de habitantes de 1945; las guerras civiles se han multiplicado y han causado cinco millones de muertos en los últimos 10 años; se agrega el fenómeno de las limpiezas étnicas, el problema del medio ambiente, la plaga del sida y malaria y la creciente marea de la pobreza... La crisis financiera de Asia, 1997, las protestas contra la Organización Mundial del Comercio en Seattle, 1999, los acontecimientos de Kosovo, 1998, así como el proceso de Pinochet son tres ejemplos de que estamos viviendo una nueva era". Kofi Annan invita a todos los Estados a firmar el protocolo de Kioto y a ratificar los estatutos de la Corte Penal Internacional.

Como un punto central del debate ha sido la conveniencia de poner bajo el control de la ONU la estabilización pacífica de Irak y las fuerzas de seguridad internacional bajo la supervisión del Consejo de Seguridad, tangencialmente se hicieron propuestas de reorganización de este Consejo. Tanto $\mathrm{K}$. Annan como J. Chirac proponen que nuevos países de Asia, Africa y América Latina se integren al número de miembros permanentes, citando, entre otros, a Alemania, Japón, Brasil. G. Schroder aboga por una legitimidad del Consejo de Seguridad, más representativo de todas las regiones. Una reforma y una ampliación a favor de los representantes de los países en desarrollo. "Alemania está dispuesta a asumir una mayor responsabilidad en el marco de esta reforma". (Le Monde, 25.09.03)

$\mathrm{K}$. Annan, en su mensaje sobre la reforma radical de la ONU, dice que el actual Consejo de Seguridad no refleja "las realidades geopolíticas del siglo XXI". Debe ser más representativo para que sus decisiones queden legitimadas. El cree que debe modernizarse la Asamblea General, porque da lugar a debates repetitivos y estériles que interesan a pocos países y no dejan espacio a problemas realmente más importantes. De esa forma se toman decisiones sobre la base de "un pequeño denominador común", que no suscita mayor atención fuera de la sala. Habría que revitalizar el Consejo de Tutela, una unidad en hibernación, que figura en la Carta fundacional, o suprimirla con los votos de dos tercios de los miembros. (Le Monde, 09.09.03)

Es difícil encuadrar el cúmulo de críticas vertidas contra las Naciones Unidas: ¿burocrática, ineficiente, poco democrática? Se ha criticado su elevado presupuesto, la selección de personal, cada cual hablan- 
do distintas lenguas. ¿Para qué sirven las Naciones Unidas si no logra que se respeten sus resoluciones? ¿Cuál es la representatividad del Consejo de Seguridad y cuáles los criterios que le permitan decidir el uso de la fuerza? ¿Hay que conservar el "derecho al veto"? ¿Habrá que pensar en trasladar la sede de la ONU fuera de Nueva York? ¿Cuál es la responsabilidad de la comunidad internacional cuando un Estado no protege a sus ciudadanos? Los ciudadanos ideben estar representados en la ONU? Boutros Boutros Ghali cree llegado el tiempo de preparar "la tercera generación" de esta organización internacional, que suceda a la ONU, de la misma manera que ella sucedió a la Sociedad de Naciones. Cree que los Estados no son las estructuras adaptadas para resolver los problemas a escala mundial. Hay que asociar a los "megapolos", ONG, multinacionales.

Se han vertido múltiples ideas con ocasión de un desayuno convocado entre amigos del multilateralismo, Chirac, Lula da Silva... El presidente de Francia, revocando una petición que se hiciera en La Declaración de París, noviembre 1999, aconseja la creación del "Consejo de Seguridad Económica y Social, encargado de impulsar a los organismos internacionales para anticipar y discutir los problemas globales, el buen gobierno económico, social y medio ambiental". Repitiendo la frase de un embajador: "el problema no es la ONU; el problema es el mundo". Luego del fracaso de la OMC en Cancún, José Vidal Beneyto afirma: "Es absurdo que la OMC ignore las $\mathrm{Na}$ ciones Unidas y dé la espalda a la FAO y a la Conferencia para el Comercio y el Desarrollo, que debían ser sus mentores. La OMC de hoy no sirve; es una de las grandes asignaturas pendientes de la refundación de las Naciones Unidas, que tantos, incluyendo Kofi Annan, estamos pidiendo con urgencia". (El País, 13.09.03).

Cuando nuestro señor presidente dijo en Nueva York que "Las Naciones Unidas deben ser repensadas y reestructuradas para poder enfrentar los objetivos para que fue creada", olvida lamentablemente que a los 58 años de su fundación nuevos y distintos problemas emergen a nivel mundial y, de manera especial, que una de las grandes potencias irrespete tradicionalmente las resoluciones y mandatos de las Naciones Unidas en temas de transcendencia mundial. Igual edad que las Naciones Unidas tienen el FMI, el BM y el GATT, hoy OMC, y se les puede dirigir la misma pregunta: chan dado una respuesta a los problemas fundacionales para los que fueron creadas?. ¿Han sido

La $58^{\circ}$ reunión de la ONU: Relorma y contrareforma 
socialmente laudables los beneficios generados por el Consenso de Washington?. El problema es el mundo, no sólo las Naciones Unidas.

Para compensar el mal sabor y tristeza que nos ha podido dejar la última determinación del Consejo de Seguridad, 16 octubre, conviene destacar alguno de los aportes positivos de la ONU. Sin hablar de las 15.000 reuniones y 5,000 informes anuales, y de las arriesgadas misiones de paz de los Cascos Azules, hay que destacar la secuencia de conferencias y cumbres mundiales convocadas por las Naciones Unidas. Las cumbres del Medio Ambiente en Río Janeiro, 1992, y en Johanesburgo, 2002; La cumbre del Desarrollo Social, 1995, y la cumbre sobre Comercio y Desarrollo en Bangkok, 2000. La cumbre del Milenio 2000 y la cumbre de Monterrey para el alivio de la pobreza 2001, nombrando sólo algunas de las cumbres económicas.

Hay un detalle importante: los manifestantes pacíficos que se hacen presentes con sus críticas en todas las cumbres de los 'maestros del mundo' (Davos, G-7, FMI-BM), asisten también a las reuniones convocadas por Naciones Unidas para decir que es una institución internacional que mantiene su esperanza. Reconociendo sus debilidades, hay que decir que, en estas cumbres de la ONU, queda un espacio para las críticas al orden internacional desde la base de los grandes valores éticos y humanos. Un ejemplo, la presente $58^{\mathrm{a}}$ conferencia de las Naciones Unidas, cuyo Secretario General es el primero en solicitar una "reforma radical", frente a la intransigencia e inmoralidad de la mayor potencia del mundo.

\section{El impenitente Bush}

Después del discurso de apertura de K. Annan, en que renueva su oposición al principio de la guerra preventiva, recalca la necesidad del multilateralismo en la resolución de los grandes problemas mundiales, las amenazas duras y blandas, recomendando hacer del Consejo de Seguridad una instancia más representativa del actual mosaico mundial, tomó la palabra el presidente Bush. El corresponsal de Le Monde dice que "las Naciones Unidas reciben fríamente a G. Bush" y el de El Pais agrega: "Bush pide apoyo a la ONU sin ofrecer nada: su mensaje fue enérgico, pero a la defensiva”. He aquí, algunos párrafos.

"El Consejo de Seguridad tuvo razón al exigir la destrucción de armas y al amenazar con graves consecuencias en caso contrario; gra- 
cias a la actuación de la coalición hoy Irak es un país libre. Nuestra acción en Afganistán y en Irak recibió el apoyo de numerosos gobiernos y Norteamérica les está muy agradecida. También reconozco que algunas naciones de esta Asamblea no estaban de acuerdo con nuestra decisión. Pero había y sigue habiendo una identificación con los principios fundamentales y los objetivos de las Naciones Unidas. Ahora tenemos que trabajar juntos. Vayamos hacia delante. La letal combinación de regímenes fuera de ley, redes terroristas y armas de destrucción masiva es un peligro que no puede ser ignorado o despreciado. A medida que descubríamos campos de exterminio y fosas comunes se revela en toda su magnitud la crueldad de Saddam. El régimen de Saddam Hussein mantenía el terror fabricando armas de destrucción masiva. Las utilizaba para hacer masacres y se opuso a mostrarlas cuando el mundo se lo pidió".

"El primer objetivo de nuestra coalición en Irak es la autodeterminación del pueblo iraquí en forma ordenada y democrática. Este proceso debe desarrollarse de acuerdo a las exigencias de los iraquíes y no debe acelerarse o retrasarse de acuerdo al deseo de otras instancias. Al igual que en otros conflictos, las Naciones Unidas deben ayudar en la elaboración de una Constitución, en la formación de funcionarios y en la organización de elecciones libres y limpias. Las Naciones Unidas pueden contribuir mucho al objetivo de la autodeterminación de los iraquíes. Ahora la nación iraquí necesita y merece nuestra ayuda y todos los países dispuestos a hacer el bien deben gustosamente dar su apoyo". (Le Monde, 24.09.03. El Pais, 24.09.03)

Comparando la textura de este discurso con el desarrollo de los hechos, decisiones unilaterales y mentiras propaladas en el mes de marzo, queda patente el estrabismo mental del presidente Bush. Su discurso generó tantas críticas como decepción. Una frase de Lula da Silva resume el rechazo y el descontento: "La ONU no ha sido creada para limpiar los escombros de conflictos que ella no pudo evitar". Esta es la inmoralidad de la administración Bush, que atropella el voto de la ONU para lanzar la guerra y ahora le exige un "apoyo condicionado" para tejer una Constitución y una paz "bajo el comando de las fuerzas de ocupación'. La administración Bush no ha tomado en cuenta las enmiendas que K. Annan, J. Chirac, G. Schroder, V.Putin hicieran en la previa reunión de Ginebra llevada a cabo el 13 
septiembre, y han cerrado totalmente sus oídos a los discursos de estos signatarios.

Quedarán en los anales de esta cumbre estos discursos. "Nadie puede actuar sólo", dijo Chirac. "Nadie puede actuar sólo en nombre de todos y nadie puede aceptar la anarquía de una sociedad sin reglas. No hay alternativa a la de las Naciones Unidas. El multilateralismo es esencial, eficaz y moderno. En Irak, la transferencia de la soberanía a los iraquíes, únicos responsables de su destino, es indispensable para su estabilidad y reconstrucción. Corresponde a la ONU legitimar el proceso. La ONU debe acompañar la progresiva transferencia de las responsabilidades administrativas y económicas a las actuales instituciones iraquíes, apegados a un calendario realista, y ayudar a la elaboración de una Constitución hecha por los iraquíes y de un proceso electoral. Corresponde, en fin, a la ONU autorizar una fuerza multinacional, dirigida naturalmente por quien aporte más tropas”. Chirac recomienda que la reforma de la ONU se inspire en los principios de "democracia, autoridad y eficiencia". La responsabilidad principal del logro de la paz y seguridad corresponde al Consejo de Seguridad, cuya composición debe ampliarse con representantes de Asia, Africa y América Latina, además de sugerir Japón y Alemania. (Le Monde, 24.09.03)

G. Schröder pide también "Reforzar las Naciones Unidas. Nuestra historia nos indica la vía a seguir. La vía de una intensa cooperación internacional bajo la égida de las Naciones Unidas, que debemos reforzar con audaces reformas. Debemos reforzar el papel y el compromiso de Naciones Unidas en Irak. Sólo Naciones Unidas puede garantizar la necesaria legitimidad para permitir a la población iraquí reconstruir rápidamente su país, bajo la dirección de un gobierno independiente y representativo. Alemania se ofrece a sostener este proceso, proporcionando ayuda humanitaria, técnica y económica, incluso con la formación de fuerzas de seguridad iraquíes. Para combatir lo anárquico, debemos buscar el remedio a la ausencia de derecho. Esta es la principal misión de la Corte Suprema Internacional" (Le Monde, 25.09.03)

Luiz Inacio Lula da Silva insiste, también, en que la transición política en Irak debe confiarse más bien a la ONU que a 'la potencia ocupante', con miras a lograr "lo antes posible" la soberanía de Irak. 
"En Irak, el clima de inseguridad prevaleciente y las crecientes tensiones complican aún más la reconstrucción del país. Esta dificultad sólo puede ser resuelta bajo la dirección de Naciones Unidas. No debemos obviar nuestras responsabilidades. Una guerra puede, sin duda, ser ganada por un solo país. Pero la paz, una paz durable, no puede consolidarse sin el apoyo de todos". (Le Monde, 24.09.03) V. Putín, antes de su viaje a Nueva York, había comentado que la actual situación de Irak "era la mejor confirmación" del por qué Rusia se había opuesto a la invasión de Estados Unidos. Rusia está dispuesta a sostener una resolución de Naciones Unidas sobre Irak, si se le concede a la ONU "un papel real y no sólo ser una simple vitrina". (Le Monde, 25.09.03)

"Muchos musulmanes piensan que se ha diabolizado su religión", mientras que "el Oeste ve al mundo islámico como inestable, hostil y proclive a atacar a Occidente. El choque de civilizaciones es una mascarada". Se necesita una "modernización ilustrada". Estando reciente la quiebra de Cancún, el presidente de Senegal se hizo eco de todos los que han denunciado el desequilibrio de los intercambios comerciales internacionales, desfavorables a los países en desarrollo $\mathrm{y}$, en particular, a los africanos, anunciando una reunión cada dos años en Qatar, a modo de un Davos agrícola, que se esfuerce por encontrar una alternativa al vigente sistema comercial. (Le Monde, 25.09.03) De acuerdo a estos corresponsales, fueron muchos los dignatarios que plantearon a consideración de la Asamblea General importantes problemas mundiales, que se relegan 'a la vía muerta' ante el unilateralismo de la administración Bush que pide a la comunidad concentrarse en la limpieza de unos escombros económicos y políticos que ella produjo por cuenta propia. De nuevo, una conferencia tan larga como estéril.

\section{La estrategia del cambio sin hacer cambios}

La primera quincena de octubre es una secuencia de palabras huecas y de expectativas frustradas. Los proyectos, en plural, presentados por el gobierno de los Estados Unidos comienzan diciendo que la ONU jugará "un papel vital". El pacto franco-alemán y otros piden que la ONU tenga un "papel crucial", dando a entender que a la ONU le corresponde organizar la transición como lo ha hecho en Afganistán, y no al administrador norteamericano, Paul Bremer. (Le Monde, 02.10.03) Resulta tedioso seguir la cronología de propuestas, enmiendas, contrapropuestas similares, cuando luego de tres semanas 
de espera se llega a un desconcertante "pacto diplomático" que deja la situación en Irak tan inestable como hace seis meses. Con fecha 2 de octubre K. Annan comunica al Consejo de Seguridad que no tiene intención de enviar a Irak personal de Naciones Unidas, si la ONU no tiene a su cargo el proceso político. Prefiere que la ONU no tenga papel alguno en la transición iraquí, que situarse de nuevo en una situación ambigua, como el asesinato de Sergio Vieira de Mello, el 19 de agosto en Bagdad. Francia, Alemania y Rusia lamentan que, en las propuestas de Estados Unidos, no se hayan tomado en cuenta las enmiendas y propuestas que ellos habían hecho. (Le Monde, 03.10.03).

El mismo día, 2 de octubre, el informe de David Kay comunica que los 1.400 especialistas no habían encontrado armas de destrucción masiva; pero que sí había indicios de quererlas fabricar. "Blix reprocha a Estados Unidos su fracaso al justificar la guerra en Irak sin pruebas". (El País, 03.10.03. Le Monde, 03.10.03). Más vale resumir la cronología de los hechos con simples titulares, porque la única novedad es presentar siempre lo mismo. Cuatro días más tarde " $G$. Bush encarga a su consejera Condoleeza Rice supervisar la reconstrucción de Irak". (Le Monde, 07.10.03). "George Bush afirma que Estados Unidos tiene una clara estrategia en Irak". (Le Monde, 11.10.03) "Washington presenta a la ONU una tercera versión de su resolución sobre Irak". (Le Monde, 11.10.03).

"El agujero negro de la economía iraquí. Un informe de la ONU y del Banco Mundial destaca que la riqueza del país se ha reducido un $50 \%$ en los tres últimos años". Esto se debe a las dos décadas de guerra y a la corrupción del cruel régimen de Saddam. Para evitar que la comunidad internacional entierre su dinero en la arena con ocasión de la Conferencia de Donantes, la ONU y el Banco Mundial han desglosado en su informe los gastos más urgentes en 14 sectores básicos. La caída en picado del PIB se debe a tres hechos: "los problemas de producción de petróleo, con una disminución del $40 \%$; el déficit de electricidad, con una caída en la producción del $30 \%$, y el cierre temporal o definitivo de las empresas estatales". Calculan que la mitad de la población está actualmente en paro o subempleo y un porcentaje mayor continúa dependiendo de la ayuda alimentaria internacional. El Banco Mundial concluye su informe advirtiendo que, "dada la experiencia en las posguerras de otros países", las dificultades de la 
reconstrucción no se deben tanto a la falta de fondos como al problema de desarrollar instituciones que gestionen las inversiones". ( $E l$ País, 13.10.03). El problema se agrava cuando la administración Bush ladea a la ONU en la supervisión del proceso de reconstrucción

El tercer proyecto norteamericano sigue siendo muy confuso por lo que toca al papel de la ONU y a la aplicación del calendario de traspaso de la soberanía a las autoridades iraquíes. No se refuerza en nada el papel de la ONU en Irak. "Se autoriza la creación de una fuerza multinacional bajo el mando unificado norteamericano que, simplemente, debe rendir cuentas ante el Consejo de Seguridad 'al menos cada seis meses"”. Aunque se habla de un papel vital de la ONU, dicho papel queda supeditado a la coalición américo-británica, "con la cual la ONU coopera", y al consejo de gobierno iraquí, a quien la ONU "ayuda si las circunstancias lo permiten". El proyectopropuesta precisa que, en el intervalo, la coalición américo-británica (nunca definida como 'potencia ocupante') asume "provisionalmente" sus propias responsabilidades". Como la oposición norteamericana critica al gobierno por la creación del nuevo "grupo de estabilización de Irak", comandado por Condoleeza Rice, y la aparente declinación de D. Rumsfeld, el presidente Bush declaró: "La persona responsable soy yo". (Le Monde, 14.10. 03).

Un caso más, echando leña al fuego. Una de las reformas que se había solicitado en la presente conferencia era "suprimir el derecho de veto" de cualquier de los miembros permanentes del Consejo de Seguridad. Con fecha de 14 de octubre, John Negroponte, embajador norteamericano, impone su veto a una resolución presentada ante el Consejo de Seguridad por Siria, en nombre del grupo árabe, condenando la construcción por Israel de "un muro de seguridad en Cisjordania". El texto juzgaba que esta construcción era "ilegal de acuerdo a las normas del Derecho Internacional" y solicitaba la oposición del Consejo "a todas las actividades de colonización en los territorios ocupados y de todas las actividades que impliquen la confiscación de tierras y su anexión". Los discursos de representantes del grupo árabe han calificado esta empalizada de 150 kilómetros como "el muro expansionista de una conquista ilegal". Por su parte, John Negroponte justifica su recurso al veto aduciendo que el texto "no era equilibrado y no condenaba al terrorismo con términos explícitos. Una resolución del Consejo de Seguridad que se concentre en la fron- 
tera, no permite progresar en el objetivo de llegar a la paz y a la seguridad en la región". El representante israelí afirmó que se trata solamente de "métodos no violentos, los más eficaces para impedir el paso de terroristas y de sus armas hacia las zonas civiles" israelitas. (Le Monde, 15.10.03). La condena avalada por el "voto" de 10 miembros del Consejo de Seguridad queda anulada por "un simple veto". Semejante práctica anárquica mina la credibilidad de esta instancia de las Naciones Unidas.

\section{La confusa resolución del Consejo de Seguridad}

La diplomacia política maneja unos términos tan difíciles de entender como las opciones y derivados de los especuladores en bolsa de valores. El Consejo de Seguridad combinó una compleja amalgama de intuición y matemática política. "La ONU aprueba por unanimidad la operación norteamericana en Irak". Ante estos titulares, quienes no somos ni diplomáticos ni especuladores nos preguntamos simplemente dónde quedan los valores éticos y los principios del derecho internacional. Siendo benevolentes podríamos llegar a creer que la fatiga y el cansancio doblegó a los quince miembros del Consejo de Seguridad porque la cuarta y quinta propuesta norteamericana, cambiando algunos matices, venían a decir lo mismo que las tres primeras. La reunión del 16 de octubre dejó la impresión de ser una sesión de 'casino', donde todos juegan al "poquer del mentiroso". Mentían las propuestas de C. Powell; mentían los votos positivos de quienes no se comprometen a enviar tropas ni dinero. La única que no miente es la cada vez más compleja realidad política, económica y étnica de Irak.

Kofi Annan no percibe "cambios importantes en la tesis de la coalición, pero agradece a sus autores el hecho de tomar en cuenta que la ONU no piensa participar en la ocupación mientras no se vea su fin. Cuanto más dure la ocupación, más aumentará la resistencia”. K. Annan se remite a los efectos que esta resolución tenga "sobre el terreno". Francia, Alemania y Rusia lucharon hasta el último minuto para que se introdujeran, más explícitamente, algunas de sus enmiendas sobre 'fechas calendario' de transferencia de soberanía; pero al final prefirieron no obstaculizar la unidad del Consejo de Seguridad, en aras del mayor bien común con el menor daño posible. "Alemania, Francia y Rusia votarán la resolución estadounidense sobre Irak”. (Le Monde, 16.10.03). La diplomacia cree que es mejor un voto unánime 
que una abstención parcial, dejando siempre constancia de su parcial inconformidad con el contenido del proyecto norteamericano. Lo que en realidad tenemos es un voto parcial, cuyas consecuencias no logramos entender.

"Con el voto de la resolución 1511 y a través de un esquema inédito, una fuerza de ocupación se convierte en multinacional y autorizada por la ONU. Este montaje parece ilegal desde el punto de vista del derecho internacional, pero el Consejo es por sí mismo "fuente de derecho", y nada se le puede objetar". Las opiniones de los especialistas se dividen. Algunos piensan que lo mejor fue llegar a esta regularización. El Consejo no reaccionó ante la entrada en guerra de la Coalición; después, todas sus decisiones pierden valor por esta ambigüedad. Otros diplomáticos opinan que esta regularización es "terrible" para las Naciones Unidas. "Por lo menos, durante la guerra de Vietnam los Estados Unidos no vinieron a pedir nada a la ONU", dijo un embajador justo antes de entrar para unirse al coro de los "si". Otros analistas dicen que el Consejo ha logrado un derecho de inspección del desarrollo de la ocupación y que el personal de la ONU pueda retornar sin ser visto como un suplemento de las fuerzas de ocupación.

En realidad, Estados Unidos no ha cedido en nada. No entregarán las riendas del poder hasta que haya un gobierno elegido de acuerdo a una Constitución que aún no se ha redactado. No se han comprometido con una fecha determinada para entregar el poder a los iraquíes. La única presión es que el Consejo provisional de gobierno presente, antes del 15 de diciembre, un plan para elaborar la nueva Constitución. Algunos delegados han acompañado su voto con varias críticas, dando a entender que estaban en contra. Otros países no han disimulado que su voto no les costaba mucho: "Nuestra opinión pública no se interesa tanto por Irak. No vamos a estar peleándonos eternamente con Estados Unidos". Detrás del voto positivo, se disimula mal un veto pasivo. "Bush tiene su plan y tiene sus tropas. Ahora él sólo se expone. Si dentro de tres meses todo esto va mal, por lo menos el Consejo no es responsable".

La resolución solicita a la comunidad internacional proporcionar, "de acuerdo al mandato", tropas a esta fuerza internacional. Pide también a los Estados miembros y a las instituciones financieras internacionales "reforzar sus esfuerzos" para ayudar al pueblo iraquí a reconstruir y desarrollar la economía de su país". La resolución deja a 
K. Annan la forma de decidir la modalidad de compromiso de Naciones Unidas en Irak, pidiéndole presentar el Consejo un informe sobre el programa y el calendario para la elaboración de una Constitución y de las elecciones democráticas. K. Annan se alegra del voto: "Felicito a los miembros del Consejo de Seguridad por haber logrado este significativo acuerdo. Este resultado en una clara demostración de la voluntad de sus miembros de anteponer el interés del pueblo iraquí delante de otras consideraciones". (Le Monde, 17.10.03). Sin embargo la mayoría de los países miembros no se comprometen ni con tropas, ni con dinero. Por eso dijimos que en esa reunión de casino todos juegan al "poquer del mentiroso".

"La ONU tiene la rara habilidad de transformar en victoria diplomática los enfrentamientos más amargos y las rendiciones más obvias. Con la excusa de preservar la unidad del Consejo de Seguridad, los mismos países que a principios de este año se negaron a justificar la guerra entregaron ayer a EEUU el control de la paz". Pero Estados Unidos no ha conseguido todavía lo que más quería: tropas y dinero. "Rusia, Alemania y Francia decidieron votar a favor, aunque aseguraron que no participarán, ni con dinero ni con tropas, en el esfuerzo de guerra". C. Powell reconoció que la resolución "tendrá una repercusión favorable. Pero no creo que esta votación abra la puerta a más soldados". Dentro de tres días se pasará la bandeja en la reunión de Madrid y las instituciones financieras internacionales tendrán que ir por delante con el ejemplo, porque el patrón manda.

Cerramos el presente artículo con el testimonio de dos embajadores. "Este es el suicidio del Consejo de Seguridad. Al reconocer que EE.UU puede ocupar un país y además conseguir el respaldo de la comunidad internacional, la ONU se declara a sí misma irrelevante"."Cuando los estadounidenses atacaron Vietnam violaron la legalidad internacional, pero por lo menos no pidieron al Consejo que lo avalara".(El País, 17.10.03). Ahora completamos el eslogan: "El problema es el mundo; y la ONU también". 